\title{
The impact of coachee personality traits, propensity to trust and perceived trustworthiness of a coach, on a coachee's trust behaviour in a coaching relationship
}

\begin{tabular}{|c|c|}
\hline \multicolumn{2}{|c|}{$\begin{array}{l}\text { Authors: } \\
\text { Nicky H.D. Terblanche }{ }^{1} \\
\text { Marita Heyns }{ }^{2}\end{array}$} \\
\hline \multicolumn{2}{|c|}{$\begin{array}{l}\text { Affiliations: } \\
{ }^{1} \text { Business School, Faculty of } \\
\text { Economic and Management, } \\
\text { Stellenbosch University, Cape } \\
\text { Town, South Africa }\end{array}$} \\
\hline \multicolumn{2}{|c|}{$\begin{array}{l}{ }^{2} \text { Optentia Research Focus } \\
\text { Area, North-West University, } \\
\text { Potchefstroom, South Africa }\end{array}$} \\
\hline \multicolumn{2}{|c|}{$\begin{array}{l}\text { Corresponding author: } \\
\text { Nicky Terblanche, } \\
\text { nickyt@usb.ac.za }\end{array}$} \\
\hline \multicolumn{2}{|c|}{$\begin{array}{l}\text { Dates: } \\
\text { Received: } 01 \text { July } 2019 \\
\text { Accepted: } 24 \text { Oct. } 2019 \\
\text { Published: } 24 \text { Feb. } 2020\end{array}$} \\
\hline \multicolumn{2}{|c|}{$\begin{array}{l}\text { How to cite this article: } \\
\text { Terblanche, N.H.D., \& } \\
\text { Heyns, M. (2020). The impact } \\
\text { of coachee personality traits, } \\
\text { propensity to trust and } \\
\text { perceived trustworthiness of } \\
\text { a coach, on a coachee's trust } \\
\text { behaviour in a coaching } \\
\text { relationship. SA Journal of } \\
\text { Industrial Psychology/SA } \\
\text { Tydskrif vir Bedryfsielkunde, } \\
46(0) \text {, a1707. https://doi.org/ } \\
10.4102 / \text { sajip.v46i0.1707 }\end{array}$} \\
\hline \multicolumn{2}{|c|}{$\begin{array}{l}\text { Copyright: } \\
\text { (c) 2020. The Authors. } \\
\text { Licensee: AOSIS. This v } \\
\text { is licensed under the } \\
\text { Creative Commons } \\
\text { Attribution License. }\end{array}$} \\
\hline \multicolumn{2}{|l|}{ Read onlir } \\
\hline 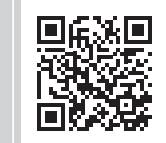 & $\begin{array}{l}\text { Scan this QR } \\
\text { code with your } \\
\text { smart phone or } \\
\text { mobile device } \\
\text { to read online. }\end{array}$ \\
\hline
\end{tabular}

Orientation: Coaching continues to grow in importance as a learning and developmental intervention in organisations. It is therefore important to understand what makes coaching successful.

Research purpose: The coaching relationship is a known predictor of coaching success, and trust is a key ingredient of a high-quality coach-coachee relationship. This study investigated whether coachee characteristics influence trust in a coaching relationship.

Motivation for the study: Research on trust from the coachees' perspective is sparse, and specifically it is not known which characteristics of the coachee influence trust behaviour (TB) in the coaching relationship.

Research approach/design and method: This study used a cross-sectional survey $(n=196)$ to measure coachees' propensity to trust, perception of the trustworthiness (TW) of their coach, TB and their Big Five personality traits. Structural equation modelling was used for analysis.

Main findings: Results revealed that neither personality traits nor propensity to trust are predictors of coachee TB. Only the extent to which the coachee perceives the coach to be trustworthy predicts coachee TB. No indirect and moderation effects were observed.

Practical/managerial implications: Coaches can actively work towards increasing their TW and by implication the TB of the coachee by demonstrating competence, integrity and ability.

Contribution/value-addition: This study makes an important contribution to the underresearched field of the role of coachees' characteristics in successful coaching engagements, in the process contributing to the understanding of what affects coaching efficacy.

Keywords: trust; trust propensity; trustworthiness; trust behaviour; executive coaching relationship; coaching; personality traits.

\section{Introduction}

Coaching is growing in importance as an intervention aiming to promote personal and professional learning and growth (Cox, Bachkirova \& Clutterbuck, 2014; Grant \& O'Connor, 2019). The dynamics of the coach-coachee relationship is an active research area in the quest to understand how coaching works (Baron \& Morin, 2009; Grant, 2014). The coach-coachee relationship is more important than any specific coaching technique or type of intervention (Bluckert, 2005; De Haan, Culpin, \& Curd, 2011; Gyllensten \& Palmer, 2007), and trust is one of the most important factors contributing to a high-quality coach-coachee relationship (Bluckert, 2005; Boyce, Jeffrey, \& Neal, 2010; Grant, 2014; Gyllensten \& Palmer, 2007; Rekalde, Landeta, \& Albizu, 2015). The factors that contribute to trust in coaching in general (Markovic, McAtavey, \& Fischweicher, 2014), and from the coachee's perspective specifically (Lu, Kong, Ferrin, \& Dirks, 2017), are however underexplored.

Trust, defined as 'a psychological state comprising the intention to accept vulnerability based upon positive expectations of the intentions or behaviours of another' (Rousseau, Burt, Sitkin, \& Camerer, 1998, p. 395), has been linked to positive coaching outcomes. Mutual trust allows a client to share and reflect more openly (Bluckert, 2005; Boyce et al., 2010) and creates a safe environment that permits the coachees to face their issues and take risks, in the process promoting growth (Boyce et al., 2010; Colquitt, Scott, \& LePine, 2007; Cox, 2012; Parker, Hall, \& Kram, 2008). 
Trust is a multidimensional concept that is interpersonal and context-specific and depends on the characteristics of both the trustor (person who trusts) and trustee (person to be trusted) (Mayer, Davis, \& Schoorman, 1995; Schoorman, Mayer, \& Davis, 2007).

In the coaching context, research has shown that characteristics of coaches influence trust (Alvey \& Barclay, 2007; Bluckert, 2005; Boyce et al., 2010; O’Broin \& Palmer, 2006; Wasylyshyn, 2003). Coaches can, for example, raise feelings of trust by being transparent about their coaching methodology (Gyllensten \& Palmer, 2007) and by displaying consistency and competence (Bluckert, 2005; Hodgetts, 2002). A coach can also transmit and generate trust in the coachee, leading to increased chances of the success of coaching (Rekalde et al., 2015). In the related field of psychotherapeutic research, similar findings suggest that therapists' characteristics, such as empathy, unconditional positive regard, respect and support, are deemed essential components of a relationship of trust (Wampold et al., 1997).

Personality traits have been shown to predict critical work behaviours (Gaddis \& Foster, 2015; Kaiser, LeBreton \& Hogan, 2015). It has therefore been suggested that the characteristics of the trustor and specifically their personality traits may influence trust (Freitag \& Traunmüller, 2009; Glanville \& Paxton, 2007). In coaching, it is however not clear how coachee (trustor) personality traits may influence trust, which is not surprising given that in the broader field of trust research, studies that focus on the follower's perspective on trust in a dyadic relationship are sparse (Lu et al., 2017).

It is evident that trust is a very important aspect of the coach-coachee relationship and, by implication, of coaching success, yet very little research has been conducted on trust and even lesser on how a coachee's characteristics influence trust. This fact was highlighted by Bozer and Jones (2018) who stated that the characteristics of coachees, which may lead to coachees developing strong perceptions of trust in their coach, deserves further investigation. To address this knowledge gap, this research investigated how the coachee's personality traits, predisposition to trust and the perceived trustworthiness (TW) of the coach influence a coachee's trust behaviour (TB).

\section{The importance of trust in coaching relationships}

The role that the coach-coachee relationship plays in coaching efficacy has emerged as an active area of research (Grant, 2014). The coaching relationship, more than any other aspect, predicts the success of the coaching intervention (De Haan et al., 2011). Specific aspects of the coaching relationship that promote coaching success include the working alliance between the coach and coachee, client self-efficacy and coaching techniques used by the coach (De Haan, Duckworth, Birch, \& Jones, 2013). Client self-efficacy in this context suggests that certain coachee characteristics may influence the coaching relationship, yet little is known about how coachee characteristics are related to improved coaching efficacy (Bozer \& Jones, 2018). Other aspects that influence the coaching relationship are closeness and commitment (Jowett, Kanakoglou, \& Passmore, 2012), with closeness defined as mutual trust and respect. This is in line with Grant's (2014) finding that empathy, unconditional positive regard and trust in a coaching relationship are predictors of the success of coaching. Gyllensten and Palmer (2007) found a valuable relationship, trust and transparency to be the three main aspects of a successful coaching relationship. They also found that trust allows the coachee to openly share personal thoughts, which assists in a positive coaching outcome.

Coachees who trust their coaches are more committed to the coaching process (Bluckert, 2005). Trust allows a coaching relationship to grow and enhances the potential for coaching success (Baron \& Morin, 2009; O'Broin \& Palmer, 2010). One study did however find that trust and coaching efficacy may be influenced by cultural factors. In a study of coaching effectiveness in Malaysia, Gan and Chong (2015) found that trust is not significantly associated with coaching efficacy. They attribute this to the generally accepted importance of trust in Asian cultures and state that coachees will by default trust their coach because of the nature of the relationship. This finding highlights the role of cultural factors and context in trust research.

From the literature reviewed so far, trust in coaching has been linked to improved listening and rapport ( $\mathrm{O}^{\prime}$ Broin \& Palmer, 2006), suggesting that trust may materially influence the very foundational elements of a coaching intervention. Trust appears to be an important and active ingredient in a successful coaching relationship, but what influences trust between a coach and coachee?

Significantly more research has been conducted on coach (as opposed to coachee) behaviour and characteristics that promote trust (Blackman, Moscardo, \& Gray, 2016). The coach must be supportive and sensitive when the coachee discloses sensitive information (Alvey \& Barclay, 2007). Good rapport is necessary for the coach to build a trusting relationship, and a coach can increase rapport, TW and trust by displaying consistent integrity and competence (Blackman et al., 2016; Bluckert, 2005).

This is echoed by Hodgetts (2002) who stated that the coach must act in a manner so as to be perceived by the coachee as being competent and trustworthy. The coach must have the ability to form strong connections, display professionalism and be transparent about the coaching methodology (Wasylyshyn, 2003). To build trust, the coach must also be predictable and reliable and exhibit empathy and authenticity (Kilburg, 1997). Furthermore, the coach's credibility in terms of their qualifications and experience influence trust (Boyce et al., 2010). Bozer, Sarros and Santora (2014) found a particular (positive) link between coaching effectiveness and a coach's academic qualification in psychology. 
The studies reviewed so far (Alvey \& Barclay, 2007; Blackman et al., 2016; Bluckert, 2005; Boyce et al., 2010; Bozer et al., 2014; Hodgetts, 2002; Kilburg, 1997; Wasylyshyn, 2003) looked at how the characteristics and behaviour of the coach influence trust in the coaching relationship. Not much however is known about the role and characteristics of the coachee in the coaching trust relationship (Bozer \& Jones, 2018; O'Broin \& Palmer, 2010). This creates a significant knowledge gap as a trust relationship is a two-way mechanism (Mayer et al., 1995), implying that the coachee also has a role to play (Blackman et al., 2016).

Research on trust outside of the coaching domain has shown that personality traits are an important consideration when studying trust (Freitag \& Bauer, 2016). In fact, a person's disposition towards trust has a significant bearing on how much they trust given specific contexts (Heyns \& Rothmann, 2015; Jeffries, 2002). It therefore seems reasonable to assume that knowledge about how a coachee's personality traits impact trust could provide valuable insights into the trust dynamics of coaching relationships.

\section{Trust, trustworthiness and propensity to trust}

Trust is multi-faceted and various perspectives exist (Heyns \& Rothmann, 2015). Historically, research into trust has been hamperedbydisagreementonthedefinitions, conceptualisations and measurement of trust (Mayer et al., 1995; McEvily \& Tortoriello, 2011), and although the field is showing signs of maturing $(\mathrm{Li}, 2017)$, it is necessary to define our interpretation of trust in this research.

\section{We use Mayer et al.'s (1995) definition of trust:}

The willingness of a party to be vulnerable to the actions of another party based on the expectation that the other will perform a particular action important to the trustor, irrespective of the ability to monitor or control that other party. (p. 712)

Furthermore, because trust is multidimensional, we employ a widely used trust model that integrates various aspects of trust developed by Mayer et al. (1995) and Schoorman et al. (2007). The 'Integrated Model of Interpersonal Trust' takes into account the interpersonal and context-specific nature of trust (Heyns \& Rothmann, 2015). The model captures the notion that trust is influenced by the trait factors of the trustor and trustee. These include the propensity of the trustor, in general, to trust, as well as the perceptions of characteristics of the trustee deemed trustworthy (Mayer et al., 1995). Three underlying constructs of TW have been established, namely, the ability, benevolence and integrity of the trustee as perceived by the trustor (Kenexa, 2012). Ability refers to a set of competencies and skills a person has within a certain domain which instils trust (Mayer et al., 1995). Benevolence refers to the extent to which the trustor perceives the trustee to act well towards him or her in a non-egocentric manner (Schoorman et al., 2007). Integrity captures the extent to which the trustor judges the trustee's level of adherence to principles that the trustor finds acceptable (Mayer et al., 1995).

This model of trust implies that trust is not a constant characteristic of an individual but rather depends on the characteristics of both parties, that is, the trustor and the trustee (Mayer et al., 1995). In the context of this research, this distinction is important as it implies that the coachee also has a role to play in the trust relationship. The coachee's propensity to trust as well as how trustworthy they perceive their coach to be may influence the trust relationship and therefore the coaching efficacy. We therefore state our first two hypotheses:

H1: A coachee's propensity to trust has a positive and statistically significant impact on a coachee's trust behaviour in a coaching relationship.

H2: The perceived trustworthiness of a coach predicts the coachee's trust behaviour.

Propensity to trust is a personality variable or stable individual difference that affects the likelihood that a person will trust (Colquitt et al., 2007), while the perception of TW influences the degree of risk that a trustor will take in a relationship (Heyns \& Rothmann, 2015). Following the theoretical model of trust proposed by Mayer et al. (1995) we hypothesise that:

H3: A coachee's propensity to trust has an indirect effect on a coachee's trust behaviour via the perceived trustworthiness of the coach.

\section{Personality traits and trust}

Is it possible that a coachee's personality traits could also influence trust? There are two perspectives on the formation of trust (Freitag \& Traunmüller, 2009). The first holds that individuals draw on past experiences to decide how much they will trust another person in similar social situations. The second challenges this notion of experienced-based trust and states that trust is a product of personality traits (Freitag \& Traunmüller, 2009; Glanville \& Paxton, 2007). Put differently, a person's personality traits predict his or her propensity to trust, their perception of another's TW and ultimately his or her level of TB.

In this research, the second perspective is considered with a focus on the coachee, and we question whether the personality traits of the coachee influence trust propensity (TP), and perception of TW and TB.

We use the Big Five traits as a measure of personality traits. The Big Five has emerged as a reliable and widely used construct for capturing a person's innate personality traits, irrespective of culture and language (Gallego \& Oberski, 2012; McCrae \& Costa, 2008; Mondak, 2010). The five traits are extraversion, agreeableness, conscientiousness, emotional stability and imagination (Mondak, 2010). Extraversion refers to a person's inclination to engage in social interaction in an active and lively manner (McCrae \& Costa, 2008). Agreeableness denotes individuals who are trusting, avoid 
conflict and engage with others in a kind and cooperative manner (McCrae \& Costa, 2008). Conscientiousness categorises people who are rational, informed and consider themselves to be competent (McCrae \& Costa, 2008). Emotional stability, also referred to as neuroticism, describes the level of negative or unpleasant emotions, thoughts and actions a person experiences (McCrae \& Costa, 2008). Imagination or openness to experience is an indication of how open a person is to new ideas, approaches and experiences (McCrae \& Costa, 2008).

Numerous studies have found associations between personality traits and aspects of the workplace including transformational leadership (Judge \& Bono, 2000; Shao \& Webber, 2006), career success (Bozionelos, 2004), leadership in a military context (McCormack \& Mellor, 2002) and leadership effectiveness (Nelson \& Hogan, 2009). It is worth mentioning that Shao and Weber's (2006) replication study (set in a Chinese context) contradicted Judge and Bono's (2000) findings (set in a Western context), implying that findings on trust should be interpreted carefully across cultural boundaries. Shao and Weber, for example, found that in China, extroversion was negatively associated with transformational leadership, whereas in the United States there was a positive association. Similarly, in the United States agreeableness was the strongest predictor of transformational leadership, whereas in China the correlation was insignificant (Shao \& Weber, 2006).

Few studies have explored the role of personality in coaching and the results are inconclusive. Jones, Woods and Hutchinson (2014) found a significant positive relationship between extraversion and perceived coaching effectiveness. Stewart, Palmer, Wilkin and Kerrin (2008) found that there was a positive relationship between conscientiousness, openness, emotional stability and executive coaching transfer.

Scoular and Linley (2006) considered personality similarity between the coach and the coachee to play a role in the coaching outcome. However, Duckworth and De Haan (2009) found no association between personality trait matching of the coach and coachee, and the perceived effectiveness of coaching.

Looking more closely at the link between personality and trust, Freitag and Bauer (2016) summarised a number of studies on personality traits and social trust, which provide inconclusive findings. One study showed a relationship between agreeableness (but no other traits) and trust (Mondak \& Halperin, 2008), whereas another study showed a link between all personality traits and trust (Dinesen, Nørgaard, \& Klemmensen, 2014). Other studies showed that trust is associated with extraversion, personal control, intelligence (Oskarsson, Dawes, Johannesson, \& Magnusson, 2012), optimism and a sense of control (Uslaner, 2002). Evans and Revelle (2008) showed that interpersonal trust was related to extraversion and negative neuroticism (emotional stability), and TW was related to agreeableness and conscientiousness. To our best knowledge, no research has been conducted on the link between the Big Five traits and coachee trust.

The conclusion we draw from the cited studies on personality and workplace aspects, coaching and trust is that although associations do seem to exist, the contextual and cultural dimensions play a significant role, making it difficult to predict which of the Big Five traits may be associated with trust. In our study, we therefore expect all of the Big Five traits to have a significant association (directly and indirectly) with the trust constructs, especially as we use the inverse of neuroticism (emotional stability), and our sample is culturally diverse. We therefore hypothesise that:

H4: The Big Five personality traits of a coachee have a statistically significant impact on a coachee's trust behaviour in a coaching relationship.

H5: The Big Five personality trait of a coachee has an indirect effect on the coachee trust behaviour:

H5a: via the perceived trustworthiness of the coach.

$\mathrm{H} 5 \mathrm{~b}$ : via the trust propensity of the coachee.

From this overview, we conclude that there appears to be a link between the propensity of the coachee to trust, their perception of the TW of their coach and the ultimate level of trust they exhibit in the coaching relationship. What is more significant is that the personality traits of a coachee may also play a role in these three trust constructs.

\section{Research design}

This research employed a quantitative, cross-sectional survey design to collect data by means of a convenience sampling technique using a questionnaire. As no previous research exists, which has linked the constructs employed in this study, we do not yet know what patterns of relationships to expect and whether there would be any moderators at play. Consequently, we followed the advice of Spector (2019) who recommends that a cross-sectional design should be the method of choice in such cases. We also controlled for potential moderating effects to strengthen findings derived from a cross-sectional study as recommended by Spector (2019), as is discussed in more detail elsewhere in this article.

\section{Research participants}

Individuals who received coaching (coachees) in an organisational context were invited directly via LinkedIn and indirectly via coaches through the International Coach Federation's (ICF) global research centre, as well as the Coaches and Mentors of South Africa's (COMENSA) research committee. More than 6000 invitations were sent and 196 completed responses were received. The total sample $(n=196)$ consisted of $59 \%$ women and $41 \%$ men. The two largest age distributions were $40-49$ years (36\%) and $50-59$ years $(32 \%)$.

In terms of the coaching intervention itself, the number of coaching sessions and interval between sessions were 
captured: $30 \%$ of participants received between 1 and 5 coaching sessions; $40 \%$ between six and 10 sessions and $23 \%$ more than 10 sessions. For $79 \%$ of participants, the interval between coaching sessions was 1-4 weeks.

\section{Measuring instruments}

Four measurement instruments were used: the Mini-IPIP (Donnellan, Oswald, Baird, \& Lucas, 2006) is derived from the original Big Five inventory of Goldberg (1999) and measures the Big Five personality factors of agreeableness, conscientiousness, extraversion, emotional stability (Neuroticism) and openness to new ideas (imagination), with four items each making a total of 20 items. In this study, the items of the emotional stability (neuroticism) scale were not inversely coded so as to measure emotional stability rather than neuroticism; therefore, preference will be given to the alternative term 'emotional stability' for this scale. The Mini-IPIP had internal consistency across five studies at or well above 0.60 (Donnellan et al., 2006).

The TW questionnaire (TWQ) developed by Mayer and Davis (1999) consisted of a first section that measures one's own general inclination or propensity to trust (eight items). The second section measures perceptions of another party's TW (17 items). More particularly, TW comprises three distinct sub-components: ability (six items), benevolence (five items) and integrity (six items). During its initial standardisation, all subscales obtained excellent reliability coefficients ranging from 0.93 for ability and 0.95 for benevolence to 0.96 for integrity (Mayer \& Davis, 1999).

The final scale in this study measures actual TB within a relationship with a focal other person, which was specified in this case as the coach. The trust disclosure scale as developed by Gillespie (2003) was used for this purpose and consists of five items that indicate the extent to which a person is willing to share his or her own thoughts, ideas and feelings with the trusted party. Previous studies found the reliability of this scale to be acceptable (e.g. Cronbach's alpha > 0.8; Gillespie [2003, 2012]) and Lam, Loi and Leong [2013] reported a Cronbach's alpha value of 0.91 for this scale).

\section{Statistical analysis}

We considered both descriptive and inferential statistics. We made use of Mplus version 8.1 (Muthén \& Muthén, 19982017) to perform structural equation modelling (SEM) for the measurement and structural models, and to test indirect effects. Composite scale reliabilities $(\rho)$ were computed using a formula based on the sum of squares of standardised loadings and the sum of standardised variance of error terms (Raykov, 2009). This method is preferable to using Cronbach's alpha, which does not provide a dependable estimate of scale reliability when latent variable modelling is used (Raykov, 2009; Wang \& Wang, 2012). Although $p$-values above 0.7 were preferred, a minimum threshold value of 0.6 was considered acceptable for this study because psychological constructs were involved and most of the scales used included fewer than 10 items, in which lower values are commonly expected (Clark \& Watson, 1995; Field, 2014; Tredoux \& Durheim, 2013).

The maximum likelihood with robust standard errors (SE) estimator (MLR) was employed to assess competing measurement models, which were then evaluated against goodness-of-fit indices to pinpoint the best-fitting model. The selected measurement model was used as a basis to test associated structural models. Absolute fit indices as well as incremental fit indices were used as criteria for model fit. These included the Akaike Information Criterion (AIC) and the Bayesian Information Criterion (BIC), as well as the chisquare statistic, the root means square error of approximation (RMSEA), the Tucker-Lewis index (TLI), the comparative fit index (CFI) and the standardised root mean square residual (SRMR) (Byrne, 2012). The AIC and BIC values do not have suggested cut-off points - the model with the lower value fits the data better. Comparative fit index and TLI with critical values above 0.90 were accepted as indicators of good model fit (Wang \& Wang, 2012). For the RMSEA, values of 0.05 or less and not exceeding 0.08 were preferred indicators of close model fit (Browne \& Cudeck, 1993), with the SRMR's indicated cut-off value set at lower than 0.05 (Cangur \& Ercan, 2015). Where necessary, chi-square difference testing was done (because of the use of the MLR estimator) to make a conclusive decision with regard to competing models.

\section{Ethical consideration}

Ethical clearance for this study was obtained from the Departmental Ethics Screening Committee of the University of Stellenbosch Business School (USB DESC): USB-2018-7852.

\section{Results \\ Testing measurement models}

Three initial competing measurement models were considered: In the first model: (1), propensity was measured using seven observed variables; (2) TW was considered as a second-order factor measured using three latent variables, namely, ability (measured using six observed variables), benevolence (measured using five observed variables) and integrity (measured using five observed variables); and (3) trust disclosure behaviour was measured using five observed variables. Finally, the Big Five personality traits (4) were represented by five first-order latent factors that were each measured using a number of positively - as well as negatively - keyed items, namely, extraversion (four items), agreeableness (four items), conscientiousness (four items), emotional stability (four items) and imagination (four items).

The second model was similar to the first, except for TW which was measured using only three latent factors - ability, benevolence and integrity. The third model was similar to the first, with the exception that TW was measured as a unidimensional latent construct represented by 17 directly observed indicators. 
A measurement model that represented the best fit to the observed data was identified and compared to two proposed alternative structures (see Table 1 for the results).

It is evident from Table 1 that the first two models represent a relatively better fit to the observed data when compared to the third model, which does not meet minimum standards as the CFI and TLI values are well below the minimum threshold of 0.90. When comparing the first two models, model 2 has a slightly lower $\chi^{2}$ value of 1201.20 when compared to model 1 $\left(\chi^{2}=1225.70\right)$; however, both have significant $\chi^{2}$ values, which is not ideal $(p>0.05)$. In contrast, model 1 has the lowest AIC (19 017.91) and BIC (19 022.94) values, which point towards model 1 as the best-fitting model, while the CFI, TLI, RMSEA and SRMR values for the first two models were identical: CFI $=0.92, \mathrm{TLI}=0.92, \mathrm{RMSEA}=0.04(90 \%$ confidence interval [CI] 0.03-0.04) and SRMR $=0.06$.

Based on these results, model 1, which also offers the closest resemblance to factor structures as the theory proposes, is selected as the preferred measurement model. In model 1, all items also loaded on their respective constructs as expected; the estimates of factor loadings were all statistically significant and varied from 0.371 to 0.998 .

\section{Testing the structural model}

The means, standard deviations, reliability and correlation coefficients of the scales as calculated using Mplus rendered acceptable results ( $p \geq 0.60$ for all scales) and are reported in Table 2.

Reliabilities of the Big Five personality traits ranged from 0.60 to 0.7 . The composite reliability coefficient for the TW measure was 0.9 , with $p=0.9$ for the ability subscale, $p=0.88$ for the benevolence subscale and $p=0.76$ for the integrity subscale. The TB (disclosure) scale reported a $p$-value of 0.9 .
Considering the minimum threshold stated for this study, all scales were considered to be acceptable (Clark \& Watson, 1995; Field, 2014; Tredoux \& Durheim, 2013).

Within this sample group, individuals who tend to be open to new ideas (imagination) are highly likely to be more extrovert $(r=0.48, p<0.01)$ and to exhibit higher levels of emotional stability $(r=0.61, p<0.01)$. Likewise, a moderate but statistically significant association between conscientiousness and agreeableness is observed $(r=0.30, p<0.05)$.

Coachees who are emotionally stable exhibit a higher level of TP $(r=0.31, p<0.01)$, implying that they are likely to have a more positive trusting stance towards coaches in general. Findings further suggest that coachees who can be described as generally agreeable are more likely to perceive their coaches as trustworthy. This relationship is of medium strength, yet highly statistically significant $(r=0.30, p<0.01)$.

Furthermore, individuals who are open to new ideas (imagination) are likely to be the ones who are more willing to demonstrate TBs towards the coach and share their thoughts and feelings freely with their coaches $(r=0.34, p<0.05)$. As a final observation, there is a very large, significant association between perceptions of TW and TB $(r=0.47, p<0.05)$.

Based on the observed associations between constructs, we performed SEM to test for underlying effects between predictor variables - Big Five traits, natural inclination to trust others in general (propensity) and assumptions regarding the TW of a significant other person within a specific relationship - on the coachee's TB towards the coach. Three models were tested: model 1 (a full model containing both direct and indirect pathways) introduced paths from each of the Big Five traits to TP and TW, from TP to TW, and from TP and TW to TB. Model 2 (a direct effects model)

TABLE 1: Fit statistics of competing measurement models.

\begin{tabular}{lccccccc}
\hline Model & $\chi^{2}$ & $d f$ & AIC & BIC & CFI & TLI & RMSEA \\
\hline Model 1 & 1225.70 & 953 & 19017.91 & 19588.31 & 0.92 & 0.91 & 0.04 \\
Model 2 & 1201.20 & 939 & 19022.94 & 19639.23 & 0.92 & 0.92 & 0.04 \\
Model 3 & 1518.29 & 956 & 19319.71 & 19880.27 & 0.84 & 0.06 & 0.06 \\
\hline
\end{tabular}

$\gamma^{2}$, chi-square; $d f$, degrees of freedom; AIC, Akaike information criterion; BIC, Bayesian information criterion; TLI, Tucker-Lewis index; CFI, comparative fit index; RMSEA, root mean square error of approximation; SRMR, standardised root mean square residual.

TABLE 2: Descriptive statistics, reliability coefficients and correlations

\begin{tabular}{|c|c|c|c|c|c|c|c|c|c|c|c|}
\hline Number & Variable & $M$ & SD & $\rho$ & 1 & 2 & 3 & 4 & 5 & 6 & 7 \\
\hline 1 & B5 Ex & 2.91 & 0.63 & 0.76 & - & - & - & - & - & - & - \\
\hline 2 & B5 Ag & 4.20 & 0.61 & 0.73 & $0.25 *$ & - & - & - & - & - & - \\
\hline 3 & B5 Cons & 3.92 & 0.61 & 0.60 & -0.04 & $0.30 \dagger *$ & - & - & - & - & - \\
\hline 4 & B5 ES & 3.46 & 0.71 & 0.69 & 0.01 & 0.01 & 0.25 & - & - & - & - \\
\hline 5 & B5 $\mathrm{Im}$ & 4.08 & 0.69 & 0.68 & $0.48 \dagger * *$ & $0.40 \dagger^{*}$ & 0.14 & $0.61 \ddagger^{* *}$ & - & - & - \\
\hline 6 & $\mathrm{TP}$ & 2.91 & 0.63 & 0.72 & 0.18 & 0.16 & 0.10 & $0.31 \dagger^{* * *}$ & 0.27 & - & - \\
\hline 7 & TW & 4.36 & 0.60 & 0.91 & 0.18 & $0.30 \div * *$ & 0.11 & 0.07 & $0.28 *$ & $0.23 *$ & - \\
\hline 8 & TB & 6.12 & 1.03 & 0.93 & $0.19 *$ & 0.17 & -0.10 & 0.08 & $0.34 \dagger^{*}$ & 0.19 & $0.47 \dagger^{* *}$ \\
\hline
\end{tabular}

Note: All constructs were measured on a 5-point scale except for TB, which was measured on a 7-point scale.

TP, trust propensity; TW, trustworthiness; TB, trusting behaviour; M, mean; SD, standard deviation; B5 Ex, extroversion; B5 Ag, agreeableness; B5 Cons, conscientiousness; B5 ES, emotional stability; B5 Im, imagination.

$*, p<0.05 ; * *, p<0.01$

$\dagger, r>0.30 ; \ddagger, r>0.50$. 
specified paths from each of the predictor variables: the Big Five traits, propensity (TP) and TW to TB, that is, the inclination to disclose personal thoughts and feelings towards a coach (TB). Model 3 (a complex indirect pathways model) specified paths from each of the Big Five traits to both TP and TW, from TP to TW, and from TP and TW to TB. Table 3 displays the fit indices of the three competing models in the first part of the table.

Comparison of the fit indices of the three models indicates identical results for CFI, TLI and RMSEA. Lower AIC values of 19015.05 and 19 017.91, respectively, point towards model 3 and model 1 as the better models. However, a lower BIC value of 19564.82 accentuated model 2 as the best-fitting model. The Satorra-Bentler difference test was performed in order to reach a conclusive decision. Results highlight a significant difference between model 1 and model 2 $\left(\Delta \chi^{2}=29.03, \Delta d f=11, p<0.001\right)$. In contrast, the difference between model 1 and competing model 3 is non-significant $\left(\Delta \chi^{2}=4.98, \Delta d f=5, p>0.05\right)$.

Because findings indicate that model 1 and model 3 fit the data equally well, the larger number of parameters and the fewer degrees of freedom associated with model 1 can be eliminated in favour of the smaller model; therefore,

TABLE 3: Initial framework fit indices and standardised path coefficients.

\begin{tabular}{|c|c|c|c|}
\hline Measures & $\begin{array}{l}\text { Direct and indirect } \\
\text { pathways (Model 1) }\end{array}$ & $\begin{array}{l}\text { Direct pathways } \\
\text { (Model 2) }\end{array}$ & $\begin{array}{l}\text { Indirect pathways } \\
\text { (Model 3) }\end{array}$ \\
\hline \multicolumn{4}{|l|}{ Fit indices } \\
\hline$\chi^{2}$ & 1225.70 & 1257.41 & 1230.07 \\
\hline$d f$ & 953 & 964 & 958 \\
\hline AIC & 19017.91 & 19030.49 & 19015.05 \\
\hline BIC & 19588.31 & 19564.82 & 19569.05 \\
\hline CFI & 0.92 & 0.92 & 0.92 \\
\hline TLI & 0.91 & 0.91 & 0.91 \\
\hline RMSEA & 0.04 & 0.04 & 0.04 \\
\hline SRMR & 0.06 & 0.08 & 0.06 \\
\hline \multicolumn{4}{|c|}{ Direct pathways to trust disclosure behaviour } \\
\hline Trustworthiness & $0.39 * *$ & $0.44 * *$ & $0.45 * *$ \\
\hline Trust propensity & 0.08 & 0.08 & 0.09 \\
\hline Extraversion & -0.08 & -0.09 & - \\
\hline Agreeableness & -0.06 & -0.06 & - \\
\hline Conscientiousness & -0.14 & -0.14 & - \\
\hline Emotional stability & -0.17 & -0.18 & - \\
\hline Imagination & 0.40 & 0.43 & - \\
\hline \multicolumn{4}{|c|}{ Direct pathways to trustworthiness } \\
\hline Trust propensity & 0.18 & - & 0.18 \\
\hline Extraversion & -0.03 & - & -0.03 \\
\hline Agreeableness & 0.16 & - & 0.14 \\
\hline Conscientiousness & 0.05 & - & 0.04 \\
\hline Emotional stability & -0.18 & - & -0.20 \\
\hline Imagination & 0.28 & - & 0.33 \\
\hline \multicolumn{4}{|c|}{ Direct pathways to trust propensity } \\
\hline Extraversion & 0.20 & - & 0.20 \\
\hline Agreeableness & 0.17 & - & 0.17 \\
\hline Conscientiousness & -0.02 & - & -0.03 \\
\hline Emotional stability & 0.39 & - & 0.39 \\
\hline Imagination & 0.13 & - & -0.12 \\
\hline
\end{tabular}

$d f$, degrees of freedom; AIC, Akaike information criterion; BIC, the Bayesian information criterion; CFI, comparative fit index; TLI, Tucker-Lewis index; RMSEA, root means square error of approximation; SRMR, standardised root mean square residual.

$*, p<0.05 ; * *, p<0.01$. we chose model 3 as the best-fitting structural model. Only one significant regression was found, namely, for TW on TB. Therefore: Hypotheses 1 and 4 are not accepted. Hypothesis 2 is accepted.

\section{Indirect effects}

As a next step, the model was evaluated for indirect effects. In order to verify findings related to Hypotheses 3 and $5 \mathrm{a}$ and $5 b$, the procedure explained by Hayes (2013) was followed. Bootstrapping was used to construct two-sided bias-corrected $95 \%$ CI so as to evaluate the significance of indirect effects. No indirect effects were found, as is evidenced by all $p$-values being non-significant $(p>0.05)$, and upper and lower CIs included zero in each instance. Therefore, Hypotheses 3, 5a and $5 b$ are not accepted.

Table 4 summarises the results of indirect effects for the Big Five traits, and Figure 1 shows the standardised path coefficients estimated using Mplus.

Summing up, we conclude that perceived TW predicts TB while the Big Five traits and TP do not have any significant effect on the decision to demonstrate TB towards a coach. This implies that coach behaviours that signify competence (ability), integrity and benevolence to the coachee are likely to enhance the quality of the coaching relationship and opportunities for personal growth irrespective of the number of coaching sessions.

\section{Discussion}

This research aimed to investigate the role that a coachee's characteristics play in the coach-coachee trust relationship dynamic. Coachee characteristics were defined as personality traits (as measured by the Big Five traits), while trust encompassed the coachee's propensity to trust, the perceived TW of the coach and the actual TB of the coachee.

Our findings highlighted a moderate association between some of the Big Five traits and TP, and perceptions of TW and TB. Coachees who fall into the 'emotionally stable' Big Five category show a higher level of TP than the other Big Five traits. Coachees who belong to the 'agreeableness' trait group are more likely to have a higher TW score, while coachees having the 'imagination' (openness) trait are more likely to actively engage in TB towards their coach. Although not related to trust, research on coaching conducted by Stewart et al. (2008) found a positive correlation between the

TABLE 4: Indirect effects of the Big Five personality traits.

\begin{tabular}{lccccccc}
\hline Variable & \multicolumn{3}{c}{ Trust propensity } & & \multicolumn{3}{c}{ Trustworthiness } \\
\cline { 2 - 5 } \cline { 7 - 8 } & Est. & SE & $\mathbf{9 5 \%} \mathbf{~ C l}$ & & Est. & SE & $95 \%$ Cl \\
\hline B5-Extraversion & 0.02 & 0.04 & {$[-0.01,0.18]$} & & -0.02 & 0.16 & {$[-0.78,0.10]$} \\
B5-Agreeableness & 0.02 & 0.04 & {$[-0.02,0.17]$} & & 0.06 & 0.17 & {$[-0.77,0.21]$} \\
B5-Conscientiousness & -0.00 & 0.03 & {$[-0.08,0.04]$} & & 0.02 & 0.12 & {$[-0.13,0.32]$} \\
B5-Neuroticism & 0.04 & 0.06 & {$[-0.03,0.29]$} & & -0.09 & 0.28 & {$[-1.71,0.09]$} \\
$\begin{array}{l}\text { B5-Intellect or } \\
\text { imagination }\end{array}$ & -0.01 & 0.08 & {$[-0.44,0.05]$} & & 0.15 & 0.37 & {$[-0.12,1.91]$} \\
\hline
\end{tabular}

$\mathrm{Cl}$, confidence intervals; SE, standard errors. 


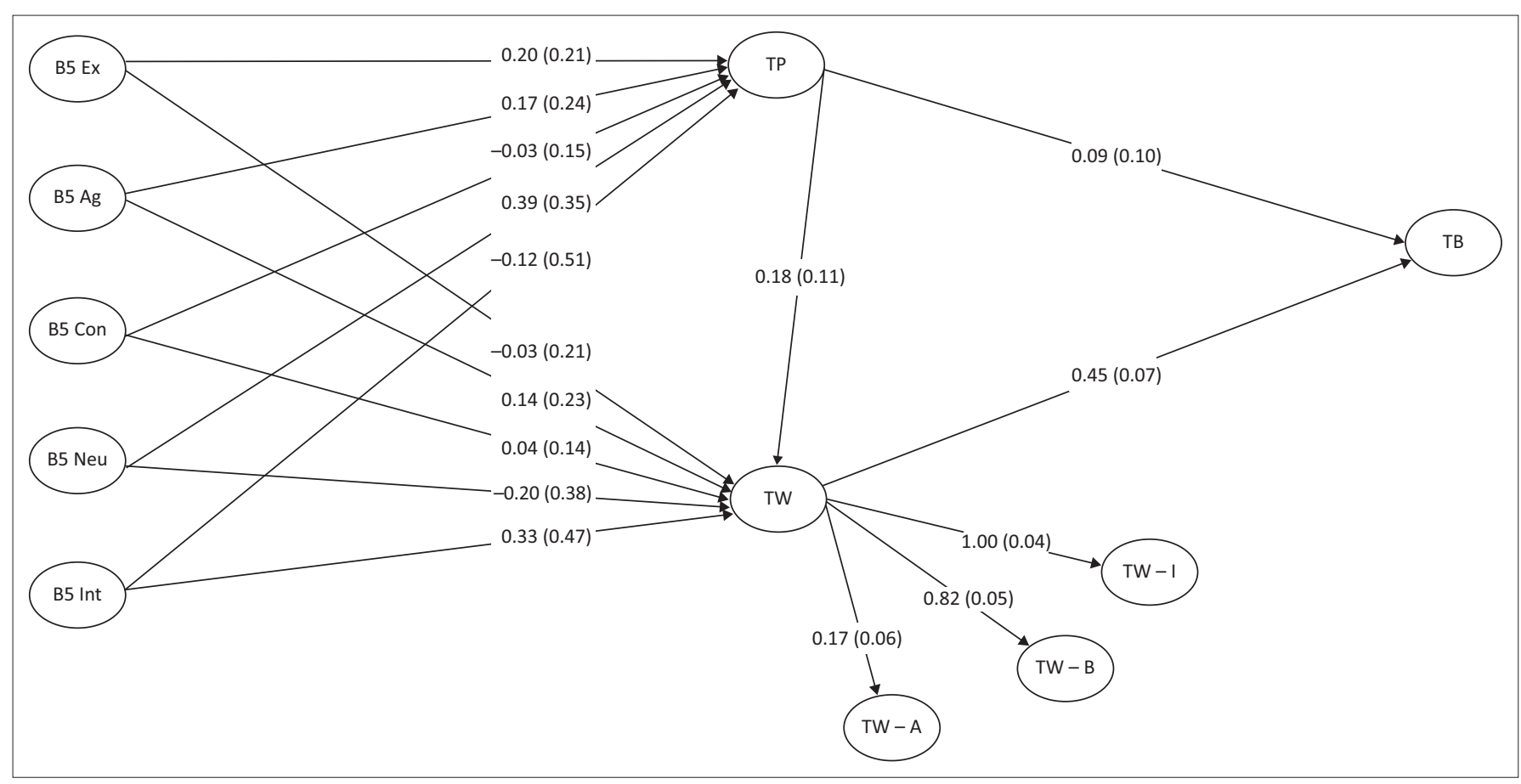

TP, trust propensity; TW, trustworthiness; TB, trusting behaviour; B5 Ex, extroversion; B5 Ag, agreeableness; B5 Cons, conscientiousness; B5 ES, emotional stability; B5 Im, imagination. FIGURE 1: The structural model (standardised solution with standard errors in parentheses).

application of coaching development and 'conscientiousness', 'openness', 'emotional stability' and 'general self-efficacy'.

The relationship between trust (broadly defined in the various studies) and the Big Five within other studies are noted. Mondak and Halperin (2008) found a relationship between 'agreeableness' and engaging in trust, whereas Hiraishi, Yamagat, Shikishima and Ando (2008) found a significant link between trust and agreeableness as well as extraversion. Dinesen et al. (2014) found that all trait groups influence trust. It is nevertheless impossible to make direct comparisons between our findings and those reported by the mentioned researchers, as the trust construct is complex and has not necessarily been conceptualised in similar ways or in similar contexts.

Turning to the more robust results of the SEM analysis, it is observed that neither the Big Five traits of a coachee nor their TP play a role in TB (H1 and H4). This initially came as a surprise, as various studies have found links between Big Five traits and TB (Dinesen et al., 2014; Freitag \& Bauer, 2016; Hiraishi et al., 2008; Mondak \& Halperin, 2008; Oskarsson et al., 2012; Uslaner, 2002). Our findings nevertheless concur with those of Heyns and Rothmann (2015), who also found that TP did not have a direct effect on TB, whereas TW beliefs indeed strongly influenced TB (Heyns \& Rothmann, 2015).

A potential explanation for these findings may lie in the fact that the historical context of a relationship (Burke, Simms, Lazzara, \& Salas, 2007; Jeffries, 2002), such as events and the frequency of interaction on an individual level, can influence the way in which trust is strengthened or weakened over time (Burke et al., 2007). A coaching relationship has a very specific, intimate nature comprising a close, confidential bond as opposed to a general type of relationship. Freitag and Bauer (2016) showed that while personality traits are important in the study of trust, the impact of personality traits on trust is weaker in trust between friends than between strangers. A coaching relationship is much more akin to a friendly relationship than to a relationship with a stranger and therefore our findings concur with those of Freitag and Bauer (2016). Furthermore, Gill et al. (2005) found that an individual's disposition to trust correlated with TB when information about TW was still lacking or ambiguous but no longer influenced TB once adequate information about TW of the trustee became clear. In line with this view, Cox (2012) and Bluckert (2005) point out that trust in coaching relationships grows over time because of the dynamic nature of relationships. In our sample, $70 \%$ of participants received six or more coaching sessions, implying a well-established relationship with a shared history and ample time to assess TW. This may explain why TP within our study did not have the expected effect on the recorded coaching relationships.

In terms of TW and TB, this research established a positive impact of the perceived TW of the coach on the coachee's TB (H2). This implies that when a coachee perceives his or her coach to be trustworthy, he or she will be more inclined to engage in TB. This is in line with previous research, albeit in a non-coaching context (Gill et al., 2005; Heyns \& Rothmann, 2015; Mayer et al., 1995). In terms of coaching, the result concurs with several studies on trust and coach characteristics. Hodgetts (2002, p. 208) found that selecting the right on the 'competence and TW' of the coach. Bluckert (2005) pointed out that a coach's competence and integrity are important contributors to trust, and according to Boyce et al. (2010) a coachee's perception of a coach's credentials and experience influences trust. 
This result (H2) implies that coaches who display ability (competence), integrity and benevolence enhance their TW in the eyes of their coachees and this in turn leads to TB from the coachee. Ability refers to the coach's skills, qualifications and experience (Boyce et al., 2010) - the 'can-do' aspect of TW (Colquitt et al., 2007), reflected in the fact that in organisational coaching, many executives prefer coaches who have management experience (Stern, 2004). Coaches can strengthen their ability by obtaining formal coaching qualifications, or by undergoing certification from a reputable coaching body (Bennett \& Bush, 2009). Integrity of coaches depends on them keeping their promises and sharing valid information (Markovic et al., 2014). A coachee may judge his or her coach's integrity by observing the coach's consistency in behaviour, words and action, and enquiring about his or her reputation (Mayer et al., 1995). Benevolence refers to a coach's intention to act in the best interest of the coachee and corresponds to the 'will-do' aspect of TW (Colquitt et al., 2007). A coach can demonstrate benevolence by providing support, showing empathy and being non-judgemental (Markovic et al., 2014).

Hypothesis 5 measured the indirect effect of Big Five traits on TB via TW (H5a) and TB (H5b).

Both hypotheses were rejected pointing to the fact that the development of positive TW perceptions is not preceded by the coachee's personality traits, but TW perceptions are rather influenced by alternative considerations relevant to the coaching relationship. Furthermore, propensity did not seem to influence the relationship between TW and trust (H3). This finding is in line with previous research conducted by Heyns and Rothmann (2015) who also concluded that once information about the TW of a trusted party becomes clear, one's disposition to trust does not seem to play an influential role any longer. These findings therefore seem to favour the notion that alternative (contextual) factors rather than personality traits are decisive in the formation of trust, also within coaching relationships.

\section{Practical implications}

This research showed that coachee personality traits do not impact the coach-coachee trust relationship. It therefore puts into question the practice in some organisations where coach-coachee matching is performed using personality assessments (Wycherley \& Cox, 2008).

The most significant finding of this research is that coaches can play an active role in the trust relationship by demonstrating TW behaviour in the form of ability, benevolence and integrity. Apart from the fact that coaches should regularly reflect on how they comply with these three aspects, coaches should also discuss their perception of the three constructs with their coaching supervisors. Coach training providers should ensure that these aspects are included in coaching training programmes. Furthermore, Human Resource Development (HRD) practitioners responsible for procuring coaching services should verify whether the coaches they employ are aware of these dynamics. In practice, coaches can demonstrate these three aspects during coaching interventions as further discussed.

Ability can be revealed by the coach sharing with the coachee his/her training methods, certification and experience at the onset of the coaching intervention or by ensuring an up-to-date Curriculum Vitae on social media. To share their credentials, coaches must of course ensure proper training at a reputable institution such as a university, as well as certification through a recognised coaching body. By participating in research and industry activities, coaches can also improve their perceived competence. Throughout the coaching intervention, the coaches should consistently demonstrate their competence and avoid overstepping the coaching boundary by venturing into advice-giving or psychotherapy territory where they may be perceived as incompetent (Bluckert, 2005).

Benevolence needs to be demonstrated throughout the coaching intervention through behaviours such as being non-judgemental, support and empathy for the client's situation. This is particularly true in cases where the coach and coachee are from different cultural backgrounds (Schoorman et al., 2007).

Integrity can be exhibited by the coach sharing his/her personal values and beliefs, and then acting in accordance with these throughout the coaching intervention and beyond. Coaches often source clients through references, implying that a breach in integrity could harm future work prospects (Markovic et al., 2014). Integrity is also demonstrated when the coach acts in a transparent manner by, for example, explaining the coaching process and then adhering to it. Predictable and reliable behaviour of the coaches will also highlight their integrity (Kilburg, 1997).

The fact that a coach's ability plays such an important role in TW and ultimately in the success of coaching adds to the debate about whether coaches should be registered and credentialed (Bachkirova \& Borrington, 2018). This finding suggests that coaching as a profession would do itself a favour by encouraging membership of recognised coaching bodies.

\section{Limitations and future research}

This research focussed on personality traits and trust constructs of TP, TW and TP and did not explicitly include demographics of coachees. Future research could investigate the role of race, gender, age and culture in TP, perceived TW and TB of both coach and coachee separately and in relation to each other.

While the sample size of 196 was adequate for this research, a larger sample may yield more robust statistical results. The challenge is to recruit large samples of coachees. In this research, more than 6000 invitations were sent to coaches requesting them to ask their clients to participate. The response rate was very low, probably because of the confidential nature 
of the coach-coachee relationship and coaches therefore being reluctant to involve their clients in non-coaching activities such as research. Future research should devise alternative strategies to involve a larger number of coachees.

This research restricted participants to those who received coaching in an organisational context, but did not discriminate between internal and external coaches. It is quite possible that trust relationships are affected by the internal or external nature of a coach and more research into these differences would be interesting. The detailed nature of the coaching interventions was also not recorded. Future research should investigate how the type of coaching approach, mode of delivery (in-person or remote), coaching aim and level of sponsor involvement influence trust.

\section{Conclusion}

This research contributes to the underexplored field of trust in coaching relationships and specifically the role that coachee characteristics play in coach-coachee trust dynamics. We found that while there are moderate associations between some of the Big Five traits and TP, and perceptions of TW and $\mathrm{TB}$, there is no evidence that personality traits either directly or indirectly impact TP, and perceptions of TW or TB. Only positive perceptions regarding the TW of a coach have a decisive influence on the extent to which trust can deepen within the coach-coachee relationship. The coach can play an active role in building the perceived TW by demonstrating ability, benevolence and integrity. These findings help shed light on factors that influence the coach-coachee relationship and by implication the coaching success.

\section{Acknowledgements}

\section{Competing interests}

The authors have declared that no competing interests exist.

\section{Authors' contributions}

All authors contributed equally to this work.

\section{Funding information}

This research received no specific grant from any funding agency in the public, commercial or not-for-profit sectors.

\section{Data availability statement}

Data sharing is not applicable to this article.

\section{Disclaimer}

The views and opinions expressed in this article are those of the authors and do not necessarily reflect the official policy or position of any affiliated agency of the authors.

\section{References}

Alvey, S., \& Barclay, K. (2007). The characteristics of dyadic trust in executive coaching Journal of Leadership Studies, 1(1), 18-27. https://doi.org/10.1002/jls.20004
Bachkirova, T., \& Borrington, S. (2018). Old wine in new bottles: Exploring pragmatism as a philosophical framework for the discipline of coaching. Academy of
Management Learning and Education, 18(3), 337-360. https://doi.org/10.5465/ Management Learn
amle.2017.0268

Baron, L., \& Morin, L. (2009). The coach-coachee relationship in executive coaching: A field study. Human Resource Development Quarterly, 20(1), 85-106. https://doi. org/10.1002/hrdq.20009

Bozer, G., \& Jones, R.J. (2018). Understanding the factors that determine workplace coaching effectiveness: A systematic literature review. European Journal of Work and Organizational Psychology, 27(3), 342-361. https://doi.org/10.1080/135943 2X.2018.1446946

Bennett, J., \& Bush, M.W. (2009). Coaching in organizations: Current trends and future opportunities. OD Practitioner, 41(1), 1-7.

Blackman, A., Moscardo, G., \& Gray, D.E. (2016). Challenges for the theory and practice of business coaching: A systematic review of empirical evidence. Human Resource Development Review, 15(4), 459-486. https://doi.org/10.1177/153448 4316673177

Bluckert, P. (2005). Critical factors in executive coaching: The coaching relationship. Industrial and Commercial Training, 37(7), 336-340. https://doi.org/10.1108/ 00197850510626785

Boyce, L.A., Jeffrey Jackson, R., \& Neal, L.J. (2010). Building successful leadership coaching relationships: Examining impact of matching criteria in a leadership coaching program. Journal of Management Development, 29(10), 914-931. https://doi.org/10.1108/02621711011084231

Bozer, G., Sarros, J., \& Santora, J. (2014). Academic background and credibility in executive coaching effectiveness. Personnel Review, 43(6), 881-897. https://doi. org/10.1108/PR-10-2013-0171

Bozionelos, N. (2004). The big five of personality and work involvement. Journal of Managerial Psychology, 19(1), 69-81. https://doi.org/10.1108/02683940410520664

Browne, M.W., \& Cudeck, R. (1993). Alternative ways of assessing model fit. In K.A Bollen \& J.S. Long (Eds.), Testing structural equation models (pp. 136-162). Newbury Park, CA: Sage.

Burke, C.S., Simms, D.E., Lazzara, E.H., \& Salas, E. (2007). Trust in leadership: A multilevel review and integration. The Leadership Quarterly, 18(6), 606-632. https:// doi.org/10.1016/j.leaqua.2007.09.006

Byrne, B.M. (2012). Structural equation modeling with Mplus: Basic concepts, applications and programming. New York: Routledge.

Cangur, S., \& Ercan, I. (2015). Comparison of model fit indices used in structural equation modeling under multivariate normality. Journal of Modern Applied Statistical Methods, 14(1), 152-167. https://digitalcommons.wayne.edu/jmasm/ vol14/iss1/14

Clark, L.A., \& Watson, D. (1995). Construct validity: Basic issues in objective scale development. Psychological Assessment, 7(3), 309-319. https://doi.org/10.1037/ 1040-3590.7.3.309

Colquitt, J.A., Scott, B.A., \& LePine, J.A. (2007). Trust, trustworthiness, and trust propensity: A meta-analytic test of their unique relationships with risk taking and job performance. Journal of Applied Psychology, 92(4), 909. https://doi.org/ 10.1037/0021-9010.92.4.909

Cox, E. (2012). Individual and organizational trust in a reciprocal peer coaching context. Mentoring and Tutoring: Partnership in Learning, 20(3), 427-443. https:// doi.org/10.1080/13611267.2012.701967

Cox, E., Bachkirova, T., \& Clutterbuck, D. (2014). Theoretical traditions and coaching genres: Mapping the territory. Advances in Developing Human Resources, 16(2), 139-160. https://doi.org/10.1177/1523422313520194

De Haan, E., Culpin, V., \& Curd, J. (2011). Executive coaching in practice: What determines helpfulness for clients of coaching? Personnel Review, 40(1), 24-44. https://doi.org/10.1108/00483481111095500

De Haan, E., Duckworth, A., Birch, D., \& Jones, C. (2013). Executive coaching outcome research: The contribution of common factors such as relationship, personality match, and self-efficacy. Consulting Psychology Journal: Practice and Research, 65(1), 40. https://doi.org/10.1037/a0031635

Dinesen, P.T., Nørgaard, A.S., \& Klemmensen, R. (2014). The civic personality: Personality and democratic citizenship. Political Studies, 62(Suppl 1), 134-152. https://doi.org/10.1111/1467-9248.12094

Donnellan, M.B., Oswald, F.L., Baird, B.M., \& Lucas, R.E. (2006). The Mini-IPIP scales: Tiny-yet-effective measures of the big five factors of personality. Psychological Assessment, 18(2), 192-203. https://doi.org/10.1037/1040-3590.18.2.192

Duckworth, A., \& De Haan, E. (2009). What clients say about our coaching. Training Journal, 2009, 64-67.

Evans, A.M., \& Revelle, W. (2008). Survey and behavioral measurements of interpersonal trust. Journal of Research in Personality, 42(6), 1585-1593.

Field, A. (2014). Discovering statistics using IBM SPSS statistics (4th edn.). London: Sage.

Freitag, M., \& Bauer, P.C. (2016). Personality traits and the propensity to trust friends and strangers. The Social Science Journal, 53(4), 467-476. https://doi.org/ 10.1016/j.soscij.2015.12.002

Freitag, M., \& Traunmüller, R. (2009). Spheres of trust: An empirical analysis of the foundations of particularised and generalised trust. European Journal of Political Research, 48(6), 782-803. https://doi.org/10.1111/j.1475-6765.2009.00849.x

Gaddis, B.H., \& Foster, J.L. (2015). Meta-analysis of dark side personality characteristics and critical work behaviors among leaders across the globe: Findings and implications for leadership development and executive coaching. Applied Psychology, 64(1), 25-54. https://doi.org/10.1111/apps.12017 
Gallego, A., \& Oberski, D. (2012). Personality and political participation: The mediation hypothesis. Political Behavior, 34(3), 425-451. https://doi.org/10.1007/s11109011-9168-7

Gan, G.C., \& Chong, C.W. (2015). Coaching relationship in executive coaching: A Malaysian study. Journal of Management Development, 34(4), 476-493. https:// doi.org/10.1108/JMD-08-2013-0104

Gill, H., Boies, K., Finegan, J.E., \& McNally, J. (2005). Antecedents of trust: Establishing a boundary condition for the relation between propensity to trust and intention to trust. Journal of Business and Psychology, 19(3), 287-302. https://doi. to trust. Journal of Business

Gillespie, N. (2003). Measuring trust in work relationships: The behavioral trust inventory. Paper presented at the Academy of Management Conference, Seattle, WA.

Gillespie, N. (2012). Measuring trust in organizational context: An overview of survey-based measures. In F. Lyon, G. Möllering \& M.N.K. Saunders (Eds.) Handbook of research methods on trust (pp. 175-188). Cheltenham: Edward Elgar Publishing.

Glanville, J.L., \& Paxton, P. (2007). How do we learn to trust? A confirmatory tetrad analysis of the sources of generalized trust. Social Psychology Quarterly, 70(3) 230-242. https://doi.org/10.1177/019027250707000303

Goldberg, L.R. (1999). A broad-bandwidth, public-domain, personality inventory measuring the lower-level facets of several five-factor models. In I. Mervielde, I.J. Deary, F. De Fruyt \& F. Ostendorf (Eds.), Personality psychology in Europe (Vol. 7, Deary, F. De Fruyt \& F. Ostendorf (Eds.), Pers
pp. 7-28). Tilburg: Tilburg University Press.

Grant, A.M. (2014). Autonomy support, relationship satisfaction and goal focus in the coach-coachee relationship: Which best predicts coaching success? Coaching: An International Journal of Theory, Research and Practice, 7(1), 18-38. https://doi.or
Inter. International Journal of Theory, Resear
$\mathrm{g} / 10.1080 / 17521882.2013 .850106$

Grant, A., \& O'Connor, S. (2019). A brief primer for those new to coaching research and evidence-based practice. The Coaching Psychologist, 15(1), 3.

Gyllensten, K., \& Palmer, S. (2007). The coaching relationship: An interpretative phenomenological analysis. International Coaching Psychology Review, 2(2), 168-177.

Hayes, A.F. (2013). Introduction to mediation, moderation, and conditional process analysis. London: The Guilford Press.

Heyns, M., \& Rothmann, S. (2015). Dimensionality of trust: An analysis of the relations between propensity, trustworthiness and trust. SA Journal of Industria Psychology, 41(1), 01-12. https://doi.org/10.4102/sajip.v41i1.1263

Hiraishi, K., Yamagata, S., Shikishima, C., \& Ando, J. (2008). Maintenance of genetic variation in personality through control of mental mechanisms: A test of trust, extraversion, and agreeableness. Evolution and Human Behavior, 29(2), 79-85. https://doi.org/10.1016/j.evolhumbehav.2007.07.004

Hodgetts, W.H. (2002). Using executive coaching in organizations: What can go wrong (and how to prevent it). In C. Fitzgerald \& J.G. Berger (Eds.), Executive coaching: Practices and perspectives (pp. 203-223). Palo Alto, CA: Davis-Black.

Jeffries, F.L. (2002). Subjective norms, dispositional trust, and initial trust development. Journal of Behavioral and Applied Management, 3(2), 129-139.

Jones, R., Woods, S.A., \& Hutchinson, E. (2014). The influence of the Five Factor Model of personality on the perceived effectiveness of executive coaching. International Journal of Evidence Based Coaching and Mentoring, 12(2), 109-118.

Jowett, S., Kanakoglou, K., \& Passmore, J. (2012). The application of the 3+ 1Cs relationship model in executive coaching. Consulting Psychology Journal: Practice and Research, 64(3), 183. https://doi.org/10.1037/a0030316

Judge, T.A., \& Bono, J.E. (2000). Five-factor model of personality and transformational leadership. Journal of Applied Psychology, 85(5), 751. https://doi.org/10.1037/ 0021-9010.85.5.751

Kaiser, R.B., LeBreton, J.M., \& Hogan, J. (2015). The dark side of personality and extreme leader behavior. Applied Psychology, 64(1), 55-92. https://doi.org/ 10.1111/apps.12024

Kenexa. (2012). High Performance Institute Work Trends report. Retrieved from https://www.kenexa.com/ThoughtLeadership/WorkTrendsReports/TrustMatters.

Kilburg, R.R. (1997). Coaching and executive character: Core problems and basic approaches. Consulting Psychology Journal: Practice and Research, 49(4), 281-299. https://doi.org/10.1037/1061-4087.49.4.281

Lam, L.W., Loi, R., \& Leong, C. (2013). Reliance and disclosure: How supervisory justice affects trust in supervisor and extra-role performance. Asia Pacific Journal of Management, 30(1), 231-249. https://doi.org/10.1007/s10490-011-9249-5

Li, P.P. (2017). The time for transition: Future trust research. Journal of Trust Research, 7(1), 1-14. https://doi.org/10.1080/21515581.2017.1293772

Lu, S.C., Kong, D.T., Ferrin, D.L., \& Dirks, K.T. (2017). What are the determinants of interpersonal trust in dyadic negotiations? Meta-analytic evidence and implications for future research. Journal of Trust Research, 7(1), 22-50. https:// doi.org/10.1080/21515581.2017.1285241

Markovic, J., McAtavey, J.M., \& Fischweicher, P. (2014). An integrative trust model in the coaching context. American Journal of Management, 14(1-2), 102-110.
Mayer, R.C., \& Davis, J.H. (1999). The effect of the performance appraisal system on trust for management: A field quasi-experiment. Journal of Applied Psychology, 84(1), 123-136. https://doi.org/10.1037/0021-9010.84.1.123

Mayer, R.C., Davis, J.H., \& Schoorman, F.D. (1995). An integrative model of organizational trust. Academy of Management Review, 20(3), 709-734. https:// doi.org/10.5465/amr.1995.9508080335

McCormack, L., \& Mellor, D. (2002). The role of personality in leadership: An application of the five-factor model in the Australian military. Military Psychology 14(3), 179-197. https://doi.org/10.1207/S15327876MP1403_1

McCrae, R.R., \& Costa, P.T. (2008). Empirical and theoretical status of the five-factor model of personality traits. The SAGE handbook of personality theory and assessment (Vol. 1, pp. 273-294). Los Angeles, CA: SAGE Publications.

McEvily, B., \& Tortoriello, M. (2011). Measuring trust in organisational research: Review and recommendations. Journal of Trust Research, 1(1), 23-63. https://doi. org/10.1080/21515581.2011.552424

Mondak, J.J. (2010). Personality and the foundations of political behavior. New York: Cambridge University Press.

Mondak, J.J., \& D Halperin, K. (2008). A framework for the study of personality and political behaviour. British Journal of Political Science, 38(2), 335-362. https://doi. political behaviour. British Journal of
$\mathrm{org} / 1017 / \mathrm{S} 0007123408000173$

Muthén, L.K., \& Muthén, B.O. (1998-2017). Mplus user's guide (8th edn.). Los Angeles, CA: Muthén \& Muthén.

Nelson, E., \& Hogan, R. (2009). Coaching on the dark side. International Coaching Psychology Review, 4(1), 9-21.

O'Broin, A., \& Palmer, S. (2006). The coach-client relationship and contributions made by the coach in improving coaching outcome. The Coaching Psychologist, 2(2), 16-20.

O'Broin, A., \& Palmer, S. (2010). Exploring key aspects in the formation of coaching relationships: Initial indicators from the perspective of the coachee and the coach Coaching: An International Journal of Theory, Research and Practice, 3(2), 124-143. https://doi.org/10.1080/17521882.2010.502902

Oskarsson, S., Dawes, C., Johannesson, M., \& Magnusson, P.K.E. (2012). The genetic origins of the relationship between psychological traits and social trust. Twin Research and Human Genetics, 15(1), 21-33. https://doi.org/10.1375/twin.15.1.21

Parker, P., Hall, D.T., \& Kram, K.E. (2008). Peer coaching: A relational process for accelerating career learning. Academy of Management Learning and Education, 7(4), 487-503. https://doi.org/10.5465/amle.2008.35882189

Raykov, T. (2009). Interval estimation of revision effect on scale reliability via covariance structure modeling. Structural Equation Modeling, 16(3), 539-555. https://doi.org/10.1080/10705510903008337

Rekalde, I., Landeta, J., \& Albizu, E. (2015). Determining factors in the effectiveness of executive coaching as a management development tool. Management Decision 53(8), 1677-1697. https://doi.org/10.1108/MD-12-2014-0666

Rousseau, D.M., Sitkin, S.B., Burt, R.S., \& Camerer, C. (1998). Not so different after all: A cross-discipline view of trust. Academy of Management Review, 23(3), 393-404. https://doi.org/10.5465/amr.1998.926617

Schoorman, F.D., Mayer, R.C., \& Davis, J.H. (2007). An integrated model of organizational trust: Past, present, and future. The Academy of Management Review, 32(2), 334-354. https://doi.org/10.5465/AMR.2007.24348410

Scoular, A., \& Linley, P.A. (2006). Coaching, goal-setting and personality type: What matters. The Coaching Psychologist, 2(1), 9-11.

Shao, L., \& Webber, S. (2006). A cross-cultural test of the 'five-factor model of personality and transformational leadership'. Journal of Business Research, 59(8), 936-944. https://doi.org/10.1016/j.jbusres.2006.02.005

Spector, P.E. (2019). Do not cross me: Optimizing the use of cross-sectional designs. Journal of Business and Psychology 34, 125-137. https://doi.org/10.1007/ s10869-018-09613-8

Stern, L.R. (2004). Executive coaching: A working definition. Consulting Psychology Journal: Practice and Research, 56(3), 154

Stewart, L.J., Palmer, S., Wilkin, H., \& Kerrin, M. (2008). The influence of character: Does personality impact coaching success? International Journal of Evidence Based Coaching and Mentoring, 6(1), 32-42.

Tredoux, C., \& Durheim, K. (2013). Numbers, hypotheses and conclusions: A course in statistics for the social sciences. Cape Town: UCT press.

Uslaner, E.M. (2002). The moral foundations of trust. Cambridge: Cambridge University Press.

Wampold, B.E., Mondin, G.W., Moody, M., Stich, E, Benson, K., \& Hyun-nie, A. (1997). A meta-analysis of outcome studies comparing bona fide psychotherapies: Empirically, 'all must have prizes'. Psychological Bulletin, 122(3), 203-215. https:// doi.org/10.1037/0033-2909.122.3.203

Wang, J., \& Wang, X. (2012). Structural equation modelling: Applications using Mplus. West Sussex: John Wiley Sons.

Wasylyshyn, K.M. (2003). Executive coaching: An outcome study. Consulting Psychology Journal: Practice and Research, 55(2), 94. https://doi.org/10.1037/ 1061-4087.55.2.94

Wycherley, I.M., \& Cox, E. (2008). Factors in the selection and matching of executive coaches in organisations. Coaching: An International Journal of Theory, Research and Practice, 1(1), 39-53. https://doi.org/10.1080/17521880701878075 